\title{
Properties of DMF-fossil Gasoline RON95 Blends in The Consideration as The Alternative Fuel
}

\author{
Anh Tuan Hoang", Danh Chan Nguyen * \\ ${ }^{*}$ Ho Chi Minh city University of Transport, Ho Chi Minh city, Vietnam \\ E-mail: anhtuanhoang1980@gmail.com,tuan.hoang@ut.edu.vn \\ *Ho Chi Minh city University of Transport, Ho Chi Minh city, Vietnam \\ E-mail:chanck06@gmail.com
}

\begin{abstract}
The use of endless biomass sources form agricultural by-products for the renewable fuel synthesis has been being considered as the extremely useful works meeting the strict strategies of environment protection. In this work, 2,5-dimethylfuran (DMF) synthesized from available rice straw in Vietnam was mixing with fossil gasoline RON95 to determine and measure the key properties of DMF-gasoline RON95 blends based on corresponding ASTM standards in the consideration as a new alternative fuel for modern gasoline engines. Each $5 \%$ volume fraction of DMF was used for mixing purposes to create 21 samples with the change of DMF volume fractions from $0 \%$ to $100 \%$. As a result, the linearization of density, octane number, and latent heat of vaporization was conducted; meanwhile, the stoichiometric air/fuel ratio, heating value, and self-ignition temperature of DMF-gasoline RON95 blends were also reported. This work provided the full properties of blends of DMF-gasoline RON95 blends based on experimental results. Achieved results can be used for the next steps to investigate the applicability of DMF-gasoline RON95 blends to practical experiments or simulation studies.
\end{abstract}

Keywords—DMF, fossil gasoline, biomass, physical properties, gasoline engines

\section{INTRODUCTION}

Ever-increasing global demand related to fuels for transportation sectors leading to the imbalance of the demand-supply have promoted researchers to look for several renewable resources to offset the shortage of the supply [1][2]. Many years ago, the first generation renewable bio-based fuels produced from edible vegetable oil or seed resulted in the conflict in the food-chain and concerns about the economic-social growth as well as the food security [3][4]. Thus, the current efforts of the study on bioenergy production are to concentrate on utilizing endless and abundant nonfood biomass resources or municipal wastes [5][6]. Among the above-mentioned biomass resources, lignocellulose is known as the potential material for bioenergy production through biological and chemical pathways, which are is illustrated in Figure 1.

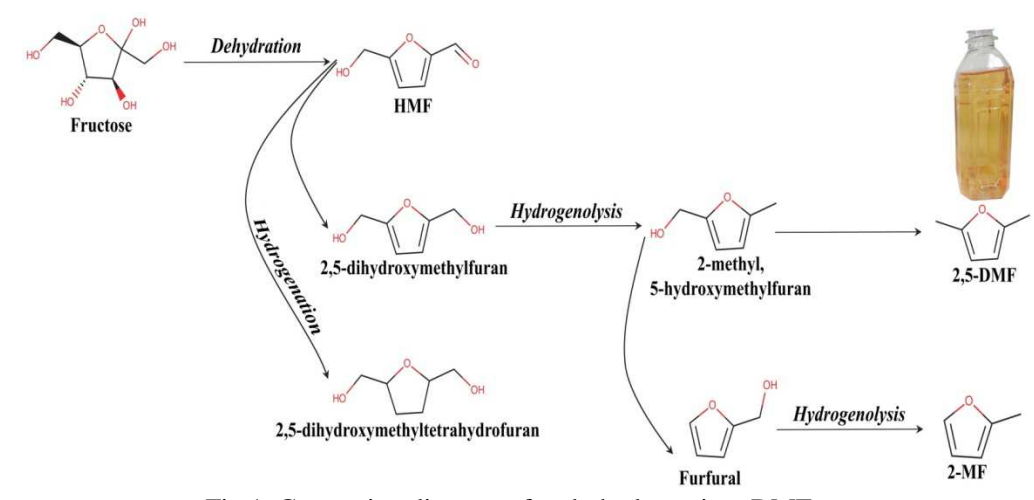

Fig 1. Converting diagram of carbohydrates into DMF 
Figure 1 shows that lignocellulose is the main component of biomass that includes wood chips, rice straw, rice husk, bagasse, sawdust, and to name just a few. The fuels originated from lignocelluloses may be included bio-oils, biogas, bio-alcohol, furan-based compounds, which are considered the second-generation biofuels. Besides lignocellulose-based absorbent materials also showed a high efficiency for the work of oil absorption to strategies of the marine environment protection [7][8]. Related to the secondgeneration biofuels, the furan-based compounds including 2,5-dimethylfuran (DMF), 5-hydroxymethyl-2-furaldehyde (HMF), 2-butylfuran (BF), 2-furfuryl alcohol (FFOH), 2methylfuran (MF), 5-ethoxymethylfurfural (EMF) are superior fuels compared to bioalcohol such as ethanol, and bio-oils due to a consumption of low energy and high yield in the synthesis process [9]. Up to now, there have been several methods for the synthesis process of furan-based fuels. Some as-used typical methods are two-step catalytic conversion [10], two chemical reactions [11], the catalysis use [12], fast pyrolysis of biomass [13]. Currently, the use of the catalysis has become more popular because the synthetic efficiency in the conversion process of biomass into DMF was higher than that of the rest methods. The utilization of blends $\left(\mathrm{Ru} / \mathrm{Co}_{3} \mathrm{O}_{4}, \mathrm{Ru} / \mathrm{Al}_{2} \mathrm{O}_{3}, \mathrm{Ru} / \mathrm{ZSM}-5, \mathrm{Co}_{3} \mathrm{O}_{4}\right)$ aiming to obtain $93.4 \%$ of the DMF synthetic efficiency was reported by $\mathrm{Zu}$ et al [14], and the application of $\mathrm{PdAu} / \mathrm{C}$ catalysis with various $\mathrm{Pd} / \mathrm{Au}$ molar ratio to achieve $99.66 \%$ of $\mathrm{DMF}$ synthetic efficiency was also found by Nishimura et al [15]. Most of published works imply that DMF is known as the suitable renewable fuel for replacement of the commercial gasoline used for internal combustion engines (ICE) [16]. DMF shows more competitive advantages regarding physicochemical properties such as higher energy density and research octane number (RON) compared to ethanolbased fuels. The insoluble property of DMF in water is an advantage over ethanol, this means that the energy of distillation process is only as $30 \%$ as that of ethanol. Additionally, vaporization heat of DMF is the same as gasoline resulting in having less cold start problems in comparison with ethanol. The volatility of DMF is also found less than ethanol due to boiling point of $20 \mathrm{~K}$ higher than ethanol [17]. Due to these properties, DMF may be useful for the strategies of the combustion control aiming at reducing the emissions and improving the efficiency of engines [18]. Several researchers have carried out the experimental studies on the use of DMF for ICE. For the combustion process, DMF was found the similarity between the laminar flame speed to that of gasoline, in addition, its laminar burning velocity was also closer to fossil gasoline than ethanol [19]. The reduction of unburnt hydrocarbon (HC), carbon monoxide (CO), soot as well as higher engine performance and lower specific fuel consumption for DMF compared to gasoline and bioethanol were found [20]. The increase in lubricity and the reduction of friction for DMF compared to gasoline and ethanol were indicated by [21][22].

In spite of strong interests of DMF, as well as taking into a consideration that DMF is found as one of the very promising additives for gasoline or DMF is directly used as potential fuel for gasoline engines in the near future, physicochemical properties of DMF are still insufficient and clearly unknown as blended with commercial gasoline based on the different fractions. This work is thus to determine the key properties of DMF-fossil gasoline RON95 blends through the achieved results from experimental measurement.

\section{MATERIALS AND METHODS}

\section{1) Material}

In this work, DMF was synthesized at the Key Lab of Chemical Engineering by using rice straw as the input material and the catalysis blends of $(\mathrm{LiCl} / \mathrm{Cu}-\mathrm{Ru} / \mathrm{Pd}-\mathrm{C})$ to provide a $97.2 \%$ of yield. After that, DMF was used for the experimental purposes without further purification. Commercial gasoline RON95 was purchase from PetroVietnam Group. The physicochemical properties of synthesized DMF and commercial gasoline RON95 were given in Table 1.

TABLE I

PROPERTIES OF DMF IN COMPARISON WiTh CONVENTIONAL GASOLINE

\begin{tabular}{|l|c|c|c|}
\hline \multicolumn{1}{|c|}{ Properties for test } & Unit & DMF & $\begin{array}{c}\text { Gasoline } \\
\text { RON95 }\end{array}$ \\
\hline Molecular formula & - & $\mathrm{C}_{6} \mathrm{H}_{8} \mathrm{O}$ & $\mathrm{C}_{2}$ - $\mathrm{C}_{14}$ \\
\hline Molecular mass & $\mathrm{g} / \mathrm{mol}$ & 96 & $100-105$ \\
\hline Water solubility at $25^{\circ} \mathrm{C}$ & $\mathrm{mg} / \mathrm{ml}$ & $\leq 1.54$ & 745 \\
\hline Density & $\mathrm{g} / \mathrm{ml}$ & 890 & Insoluble \\
\hline Oxygen content & $\%$ & 16.67 & 0 \\
\hline Stoichiometric air/fuel ratio & - & 10.72 & 14.56 \\
\hline Heating value & $\mathrm{kJ} / \mathrm{kg}$ & 33.6 & 43.2 \\
\hline $\begin{array}{l}\text { Research Octane Number } \\
\text { (RON) }\end{array}$ & - & 112 & 95.6 \\
\hline $\begin{array}{l}\text { Motor Octane Number } \\
\text { (MON) }\end{array}$ & - & 91 & 85.8 \\
\hline Self-ignition temperature & ${ }^{\circ} \mathrm{C}$ & 286 & 258 \\
\hline Latent heat of vaporization & $\mathrm{kJ} / \mathrm{kg}$ & 334 & 351 \\
\hline
\end{tabular}

From Table 1, it can be seen the advantages of DMF as followed:

- There is $16.67 \%$ of oxygen mass in the component of DMF resulting in clean and perfect combustion in comparison with gasoline RON95 (0\% of oxygen mass). Including oxygen content in the component odd DMF is a factor reducing the ratio of stoichiometric air/fuel;

- Water solubility of DMF is infinitesimal (equal to gasoline RON95), and is much lower than ethanol (>100);

- Research Octane Number (RON) and Motor Octane Number (MON) of DMF are higher than those of gasoline RON95;

- Self-ignition temperature of DMF is higher than that of gasoline RON95, this property imply that DMF is a fuel that may be used for either gasoline engines or diesel engines;

- Latent heat of vaporization of DMF is $20 \%$ lower than that of gasoline RON95, this parameter indicates that DMF is turned into vapor in the formation of air-fuel mixture more easily and faster compared to gasoline RON95.

\section{2) Methods}

In this work, the as-used DMF was mixed with fossil gasoline RON95 based on the volume percentage. The sample was created by mixing $\mathrm{x} \%$ volume percentage of DMF and (100- $\mathrm{x}) \%$ volume percentage of gasoline RON95 
to get $50 \mathrm{ml}$ of blends of DMF-gasoline RON95. There were 21 samples created for these experimental purposes, including pure DMF, gasoline RON95, and blends of DMFgasoline RON95 with each 5\% volume of added DMF. A stirrer at $100 \mathrm{rpm}$ was used to ensure the homogeneity of blends of DMF-gasoline RON95 in the mixing process, and the sampling process was based on ASTM D 4057 standard. Each measure was conducted three times to get the average result that was accepted with error lower 5\%. In addition, the standards for the test of properties of DMF-gasoline RON95 blends were given in Table 2 .

TABLE II

ASTM STANDARDS For The TeSt OF PROPERTIES OF DMF-Gasoline RON95 BLENDS

\begin{tabular}{|c|l|c|}
\hline No & \multicolumn{1}{|c|}{ Properties for test } & $\begin{array}{c}\text { ASTM } \\
\text { standard }\end{array}$ \\
\hline 1 & Density & ASTM D1298 \\
\hline 2 & Stoichiometric air/fuel ratio & ASTM D5291 \\
\hline 3 & Heating value & ASTM D3338 \\
\hline 4 & Research Octane Number (RON) & ASTM D2699 \\
\hline 5 & Motor Octane Number (MON) & ASTM D2700 \\
\hline 6 & Self-ignition temperature & ASTM E659 \\
\hline 7 & Latent heat of vaporization & - \\
\hline
\end{tabular}

\section{RESULTS AND DISCUSSION}

\section{A. Density}

Density of fuel is used to evaluate the fuel mass per a unit of volume. Normally, density of fuel is strongly affected by the distribution of molecular components as well as the carbon chain. In a relative way, density of fuel is also proportion to the kinematic viscosity and surface tension of fuel. This means that fuel with high density provides high kinematic viscosity and surface tension, and the low volatility. Density of blends of liquid fuels $\left(\rho_{\text {blends }}\right)$ can be calculated as following equation [23][24]:

$$
\rho_{\text {blends }}=\sum_{i=1}^{n} \rho_{i} m_{i}
$$

$\rho_{\mathrm{i}}$ - "i" component specific density, $\mathrm{g} / \mathrm{ml}$

$\mathrm{m}_{\mathrm{i}}$ - "i" volume fraction, $\%$

After determining the density of DMF-gasoline RON95 based on the hydrometer and ASTM D1298 standard, the obtained result was compared to the result calculated by Eq. (1) to evaluate the absolute error. The density diagram of DMF-gasoline RON95 blends measured by a hydrometer was plotted in Figure 2.

It can be clearly seen from Figure 2 that the absolute error between the density value of DMF-gasoline RON95 blends calculated by Eq. (1) and the density value of DMF-gasoline RON95 blends measured by hydrometer was very small, the maximal absolute error was $0.29 \%$. The liner correlation of the density values of DMF-gasoline RON95 blends measured by hydrometer showed $\mathrm{R}^{2}=0.999$. Thus, the empirical equation for prediction of the dependence of the density of DMF-gasoline RON95 blends was presented as followed:

$$
\rho_{\text {DMF-gasoline RON95 }}=1.445 m+746.6
$$

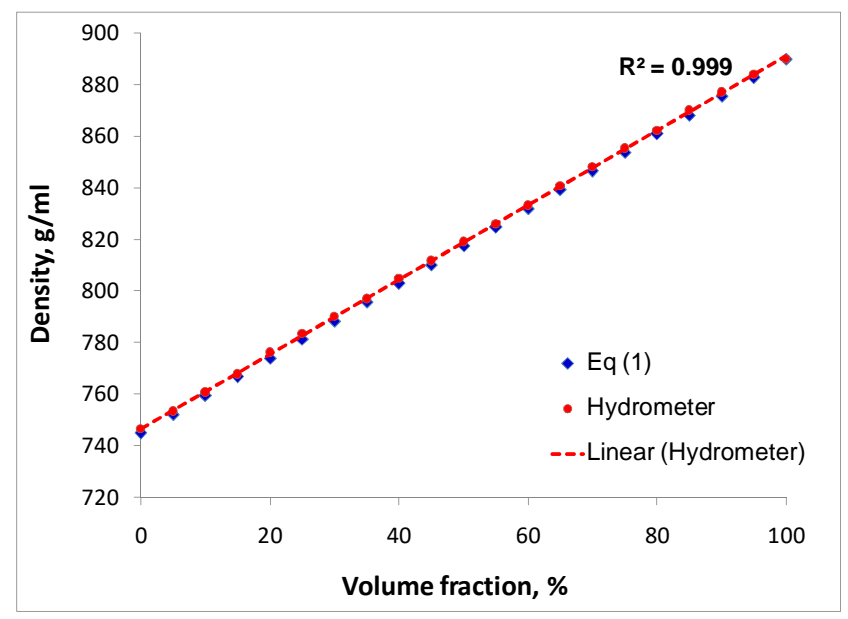

Fig 2. Relationship between DMF-gasoline RON95 blends and volume fraction

However, the achieved density values from Eq. (2) in comparison with the calculation from Eq. (1) and measured values by the above-mentioned hydrometer showed the maximal absolute error of $0.21 \%$. Hence, Eq. (2) may be used to predict the density of DMF-gasoline RON95 blends with infinitesimal absolute error.

\section{B. Heating value and self-ignition temperature}

A bomb calorimeter was used to determine heating value of as-used fuel samples based on ASTM D3338 standard. The heating value (HV) is a key parameter for combustion process of fuel in the engine. Normally, fuels with low HV cannot be combusted completely due to the released energy in the combustion is low, resulting in low output power. The HV of DMF is $22.2 \%$ lower than that of gasoline RON95 (Table 1), however, it is $24.9 \%$ higher than that of ethanol. This showed the potential of DMF as mixed with gasoline RON95. The self-ignition temperature (SIT) of fuel is thought as the lowest temperature, and SIT is determined by the pyrometer based on ASTM E659. At this temperature, fuel self-ignites in normal atmospheric condition spontaneously without the assistance of external igniter or spark plug. The HV and SIT of DMF-gasoline RON95 blends are given in Table 3.

TABLE III

\begin{tabular}{|c|c|c|c|c|c|c|c|c|c|c|}
\hline \multirow{2}{*}{ Properties } & \multicolumn{10}{|c|}{ DMF volume fraction, \% } \\
\hline & 5 & 10 & 15 & 20 & 25 & 30 & 35 & 40 & 45 & 50 \\
\hline Heating value, $\mathrm{kJ} / \mathrm{kg}$ & 42.61 & 42.08 & 41.54 & 41.06 & 40.25 & 39.98 & 39.67 & 39.02 & 38.66 & 38.18 \\
\hline \multirow[t]{3}{*}{$\begin{array}{c}\text { Self-ignition } \\
\text { temperature, }{ }^{\circ} \mathrm{C} \\
\end{array}$} & 259 & 261 & 262 & 264 & 266 & 267 & 269 & 270 & 271 & 273 \\
\hline & \multicolumn{10}{|c|}{ DMF volume fraction, \% } \\
\hline & 55 & 60 & 65 & 70 & 75 & 80 & 85 & 90 & 95 & 100 \\
\hline
\end{tabular}

Heating VAlue And Self-Ignition TeMPeRAture OF DMF-Gasoline RON95 Blends 


\begin{tabular}{|c|c|c|c|c|c|c|c|c|c|c|}
\hline Heating value, $\mathrm{kJ} / \mathrm{kg}$ & 37.71 & 37.23 & 36.78 & 36.26 & 35.88 & 35.32 & 34.91 & 34.38 & 33.92 & 33.60 \\
\hline $\begin{array}{c}\text { Self-ignition } \\
\text { temperature, }{ }^{\circ} \mathrm{C}\end{array}$ & 274 & 276 & 277 & 278 & 280 & 281 & 282 & 274 & 285 & 286 \\
\hline
\end{tabular}

From Table 3, the decrease of $\mathrm{HV}$ of DMF-gasoline RON95 blends can be clearly seen along with the increase in DMF volume fractions; meanwhile, SIT tended to be proportional to the increase in DMF volume fractions. The higher SIT of DMF or DMF-gasoline RON95 blends compared to gasoline RON95 was considered as the advantage of fuel used for gasoline engines because the selfignition phenomenon is not desirable in the SI (spark ignition) engine that the use of spark plug for the ignition of the air-fuel mixture is required at the proper/certain time. The pressure pulses in the combustion chamber of the SI engine are generated as the self-ignition phenomenon occurs higher in comparison with desirable. The appearance of these high-pressure pulses in the combustion chamber causes the "knock" or "ping", even the damage to the engine. Obviously, SIT and HV of DMF were found higher than ethanol, and it is thus suitable for mixing/blending with gasoline to replace the as-used gasoline.

\section{Octane number}

Octane number $(\mathrm{ON})$ is an important parameter for the aim of the increase the compression ratio for gasoline engine to satisfy strategies of improving fuel economy without occurring "knock" and self-ignition in the SI gasoline engine. As reported, fuels with higher ONs can prevent the "knock" in the engine, thus, a high-compression ratio engine running on high-ON fuels may result in a reduction of specific fuel consumption as well as greenhouse gas emissions. The higher the $\mathrm{ON}$ is, the higher the flame speed to the mixture of air-fuel is. This is explained that the mixture of air-fuel in the combustion chamber heated above SIT is ignited with a higher flame speed resulting in consuming during ignition delay time, as the result, the knock is avoided. Normally, there are two most common ONs considered the world-wide regulated parameter to rate fuels used for SI engines such as Motor Octane Number (MON) and Research Octane Number (RON). In general, a good approximation with small absolute error for the determination of the mixture $\mathrm{ON}$ can be shown as following Eq. (3) [25] that $x_{i}$ is mass percentage of component "i", and $\mathrm{ON}_{\mathrm{i}}$ is octane number of component "i":

$$
O N_{\text {blends }}=\sum_{i=1}^{n} x_{i .} . O N_{i}
$$

Currently, the minimum limits related to the requirement are 95 for the RON and 85 for MON. It can be seen from Table 1 that the RON of DMF is 112 compared to 108 of ethanol and 95.6 of gasoline, and the MON of DMF is 91 compared to 88.2 of ethanol and 85.8 of gasoline. Both of RON and MON of DMF are higher than the required minimum limits based on European standards. It can be thus expected an anti-knock ranking of DMF better than ethanol and gasoline. MON and RON of DMF-gasoline RON95 blends after a test based on ASTM D2699 and ASTM D2700 and calculated by Eq. (3) are presented in Figure 3.

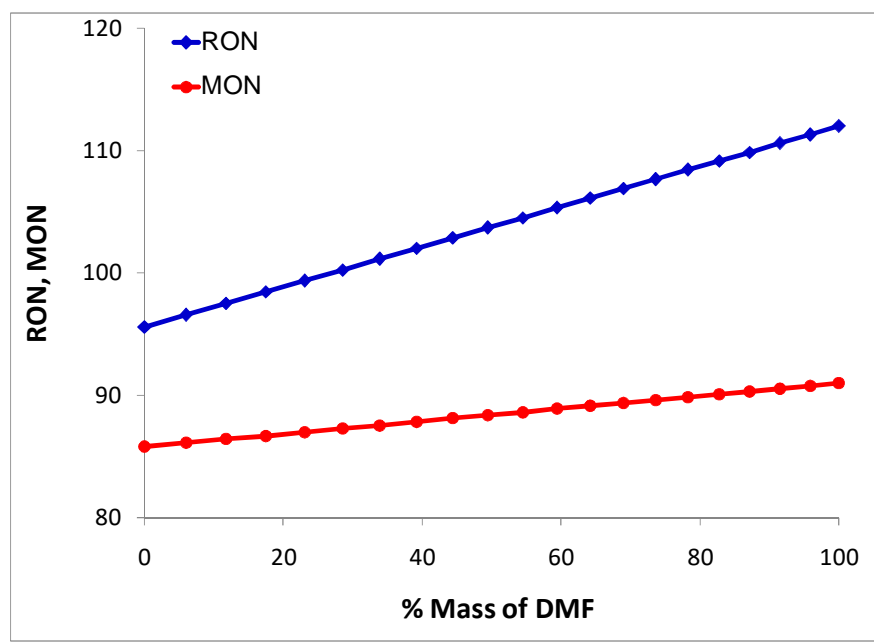

Fig 3. RON and MON of DMF-gasoline RON95 blends as a function of mass percentage of DMF

Normally, RON is found higher than MON because the measuring condition for MON is more severe than that of RON. To evaluate the difference between RON and MON, a parameter such as fuel sensitivity (FS) should be used as followed:

$$
F S=R O N-M O N
$$

FS is considered as a good and popular measure of how sensitive-knock characteristics in either the use of fuels or engine geometry. In fact, a low FS number shows that knock characteristics of the as-used fuel are not sensitive to the geometry of engines. Generally, the values of FS are from 0 to 10 for fossil gasoline. Based on Figure 3, the range of FS for DMF-gasoline RON95 blends is from 9.80 to 21.00, these FS values show much higher than those fossil gasoline and the as-used ethanol-gasoline blends.

\section{Latent heat of vaporization}

Latent heat of vaporization (LHoV), which is determined by differential scanning calorimeter, is also a critical parameter of fuel affecting the air-fuel mixture formation in the cylinder of engines. High LHoV leads to the decrease of intake-air temperature in case of engines with outsidecylinder mixture formation, and the temperature of incylinder mixture for DI (direct injection) engines because the taken energy by the charge air is to turn the fuel into vapor [26]. This means that DI engines desire a high LHoV of fuel to reduce temperatures in the cylinder as well as reduce NOx emissions and knock propensity. LHoV of DMF-gasoline RON95 blends are given in Table 4. 
TABLE IV

LATENT HEAT OF VAPORIZATION OF DMF-GASOLINE RON95 BLENDS

\begin{tabular}{|c|c|c|c|c|c|c|c|c|c|c|}
\hline \multirow{2}{*}{ Properties } & \multicolumn{10}{|c|}{ DMF volume fraction, \% } \\
\hline & 5 & 10 & 15 & 20 & 25 & 30 & 35 & 40 & 45 & 50 \\
\hline \multirow[t]{3}{*}{$\begin{array}{c}\text { Latent heat of } \\
\text { vaporization, } \mathrm{kJ} / \mathrm{kg}\end{array}$} & 350.0 & 349.0 & 348.1 & 347.1 & 346.2 & 345.2 & 344.4 & 343.5 & 342.6 & 341.8 \\
\hline & \multicolumn{10}{|c|}{ DMF volume fraction, $\%$} \\
\hline & 55 & 60 & 65 & 70 & 75 & 80 & 85 & 90 & 95 & 100 \\
\hline $\begin{array}{c}\text { Latent heat of } \\
\text { vaporization, } \mathrm{kJ} / \mathrm{kg}\end{array}$ & 340.9 & 340.1 & 339.3 & 338.5 & 337.7 & 336.9 & 336.2 & 335.5 & 334.7 & 334.0 \\
\hline
\end{tabular}

As given in Table 4, the $\mathrm{LHoV}$ values for gasoline and DMF-gasoline RON95 blends range from $334.0 \mathrm{~kJ} / \mathrm{kg}$ to $351.0 \mathrm{~kJ} / \mathrm{kg}$. The achieved results show that the decrease of LHoV of DMF-gasoline RON95 blends is because the $\mathrm{LHoV}$ of DMF is $4.84 \%$ lower than that of gasoline. The obtained results may be due to the significant difference in the carbon chain structure of DMF that composes aromatic cycle. However, the reduction of LHoV of DMF compared to gasoline is infinitesimal. Compared to the as-used ethanol, DMF showed several similar properties to gasoline and it is thus appropriate to mix and use for modern gasoline engines. Because LHoV of DMF is lower than gasoline, however DMF has oxygen component in the molecular, therefore, particle emissions are much lower than gasoline.

\section{E. Stoichiometric air-fuel ratio}

As fabricating an engine, the air-fuel ratio needs being clearly known to calculate the fuel injected into the combustion cycle as well as the used oxygen for complete combustion. The above-mentioned ratio is thought as the stoichiometric air-fuel ratio. Theoretically, stoichiometric air-fuel ratio only exists only for a chemical equilibrium for ideal mixture. Since every cycle of internal combustion engines is short lived, thus, it is almost impossible to obtain the ideal condition. In this work, a narrow band oxygen sensor is used to measure the stoichiometric air-fuel ratio based on ASTM D5291. The stoichiometric air-fuel ratio are shown in Figure 4.

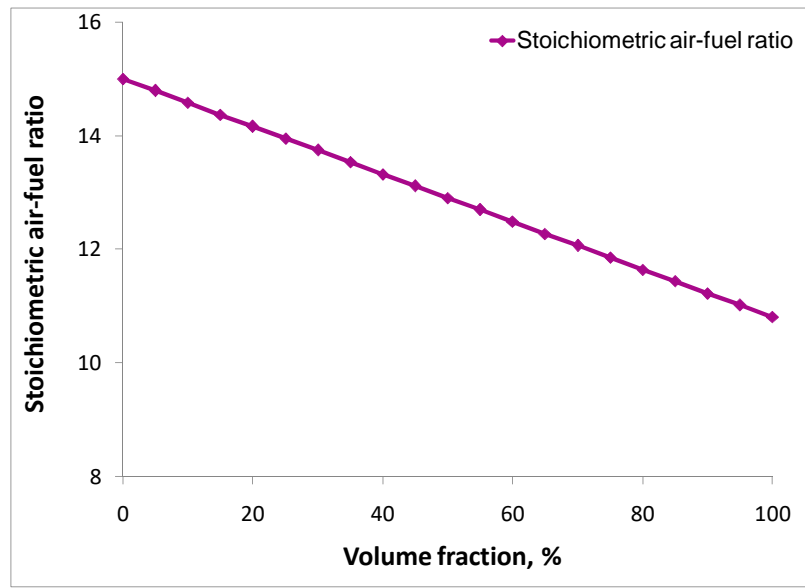

Fig 4. Stoichiometric air-DMF-gasoline RON95 ratio as a function of DMF volume fraction

From Figure 4, it can be clearly seen a reduction of stoichiometric air-fuel ratio when increase the volume fraction of DMF. This is explained because the stoichiometric air-fuel ratio of DMF is 10.81 compared to 14.96 for gasoline RON95. The appearance of oxygen component with around $16.67 \%$ of mass in DMF molecular is thought as the main factor assisting the combustion process as well as reducing the consuming oxygen. Although the stoichiometric air-fuel ratio for DMF is still higher than that of ethanol (8.96) and the mass percentage of oxygen in DMF is lower than that of ethanol $(34.78 \%)$, the heating value of DMF is $24.87 \%$ higher than ethanol. As the result, the energy density produced from the combustion for DMF is found higher than ethanol. Moreover, the water solubility of DMF (max.1.54 mg/ml) is much lower compared to ethanol (min.100 mg/ml) leading to the good compatibility between DMF and materials used for building the engines.

\section{CONCLUSIONS}

In this experimental study, a new biofuel such as 2,5dimethylfuran (DMF) produced by available biomass was mixed and blended according to each 5\% volume of DMF with fossil gasoline RON95 aiming to determine the key properties of DMF-gasoline RON95 blends in the consideration as an alternative fuel used for modern gasoline engines. After mixing with gasoline RON95, some properties of DMF-gasoline RON95 blends including density, stoichiometric air/fuel ratio, heating value, octane number, self-ignition temperature and latent heat of vaporization were measured based on ASTM standard. As a result, some advantages of DMF-gasoline RON95 blends compared to gasoline RON95 were also indicated, being low stoichiometric air/fuel ratio, high octane number and fuel sensitivity, high self-ignition temperature, and oxygen contain. Although heating value and latent heat of vaporization of DMF-gasoline RON95 blends were lower than gasoline RON95, the difference was infinitesimal. Therefore, DMF should be considered as a potential renewable fuel to replace or mix with fossil gasoline to satisfy the strict strategies and regulations related to the reduction of environmental pollution.

\section{NOMENCLATURE}

\section{DMF 2,5-dimethylfuran}

HMF 5-hydroxymethyl-2-furaldehyde

BF 2-butylfuran

FFOH 2-furfuryl alcohol

MF 2-methylfuran

EMF 5-ethoxymethylfurfural

RON Research octane number

MON Motor octane number

SIT Self-ignition temperature $\quad{ }^{\circ} \mathrm{C}$

$\mathrm{HV} \quad$ Heating value $\mathrm{kJ} / \mathrm{kg}$

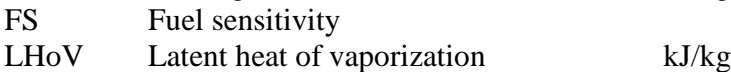




\section{REFERENCES}

[1] M. Elma, S. A. Suhendra, W. Wahyuddin, W. Saputri, and S. A. A. Utami, "Optimum Ratio Between Waste Cooking Oil and Coconut Oilas Raw Material for Biodiesel Production,” Int. J. Adv. Sci. Eng. Inf. Technol., vol. 7, no. 4, pp. 1227-1233, 2017.

[2] A. T. Hoang, "Prediction of the density and viscosity of biodiesel and the influence of biodiesel properties on a diesel engine fuel supply system," J. Mar. Eng. Technol., 2018. https://doi.org/10.1080/20464177.2018.1532734.

[3] R. Rasheed, A. Yasar, S. R. Ahmad, A. B. Tabinda, S. A. Khan, and Y. Su, "Bioenergy recovery analysis from various waste substrates by employing a novel industrial scale AD plant," Energy Sources, Part A Recover. Util. Environ. Eff., vol. 40, no. 16, pp. 1935-1946, 2018.

[4] A. T. Hoang and V. V. Pham, "A study of emission characteristic, deposits, and lubrication oil degradation of a diesel engine running on preheated vegetable oil and diesel oil," Energy Sources, Part A Recover. Util. Environ. Eff., vol. 41, no. 5, pp. 611-625, 2019.

[5] A. T. Hoang and A. T. Le, "A review on deposit formation in the injector of diesel engines running on biodiesel," Energy Sources, Part A Recover. Util. Environ. Eff., vol. 41, no. 5, pp. 584-599, 2019.

[6] A. T. Hoang, "Waste heat recovery from diesel engines based on Organic Rankine Cycle,” Appl. Energy, vol. 231, pp. 138-166, 2018.

[7] B. Bakri, "Tobermorite Microstructure Resulted from Reaction of Low Content of Silica of Rice Husk Ash and Quicklime Mixture," Int. J. Adv. Sci. Eng. Inf. Technol., vol. 8, no. 3, pp. 664-670, 2018.

[8] A. T. Hoang, X. L. Bui, and X. D. Pham, "A novel investigation of oil and heavy metal adsorption capacity from as-fabricated adsorbent based on agricultural by-product and porous polymer," Energy Sources, Part A Recover. Util. Environ. Eff., vol. 40, no. 8, pp. 929939, 2018.

[9] S. Jężak, M. Dzida, and M. Zorębski, "High pressure physicochemical properties of 2-methylfuran and 2, 5dimethylfuran-second generation biofuels," Fuel, vol. 184, pp. 334343, 2016.

[10] Y. Román-Leshkov, C. J. Barrett, Z. Y. Liu, and J. A. Dumesic, "Production of dimethylfuran for liquid fuels from biomass-derived carbohydrates," Nature, vol. 447, no. 7147, p. 982, 2007.

[11] C. M. Cai, T. Zhang, R. Kumar, and C. E. Wyman, "Integrated furfural production as a renewable fuel and chemical platform from lignocellulosic biomass," J. Chem. Technol. Biotechnol., vol. 89, no. 1, pp. 2-10, 2014.

[12] Z. Fu, Z. Wang, W. Lin, and W. Song, "Conversion of furan derivatives for preparation of biofuels over $\mathrm{Ni}-\mathrm{Cu} / \mathrm{C}$ catalyst," Energy Sources, Part A Recover. Util. Environ. Eff., vol. 39, no. 11, pp. 1176-1181, 2017.

[13] R. L. McCormick et al., "Properties of oxygenates found in upgraded biomass pyrolysis oil as components of spark and compression ignition engine fuels," Energy \& Fuels, vol. 29, no. 4, pp. 2453-2461, 2015 .
[14] Y. $\mathrm{Zu}$ et al., "Efficient production of the liquid fuel 2, 5dimethylfuran from 5-hydroxymethylfurfural over $\mathrm{Ru} / \mathrm{Co} 3 \mathrm{O} 4$ catalyst," Appl. Catal. B Environ., vol. 146, pp. 244-248, 2014.

[15] S. Nishimura, N. Ikeda, and K. Ebitani, "Selective hydrogenation of biomass-derived 5-hydroxymethylfurfural (HMF) to 2, 5dimethylfuran (DMF) under atmospheric hydrogen pressure over carbon supported PdAu bimetallic catalyst," Catal. Today, vol. 232, pp. 89-98, 2014.

[16] Z. Cheng et al., "Experimental and kinetic modeling studies of lowpressure premixed laminar 2-methylfuran flames," Proc. Combust. Inst., vol. 36, no. 1, pp. 1295-1302, 2017.

[17] H. Xu and C. Wang, "A Comprehensive Review of 2, 5Dimethylfuran as a Biofuel Candidate," Biofuels from Lignocellul. Biomass Innov. beyond Bioethanol, pp. 105-129, 2016.

[18] M. A. Eldeeb and B. Akih-Kumgeh, "Recent Trends in the Production, Combustion and Modeling of Furan-Based Fuels," Energies, vol. 11, no. 3, p. 512, 2018.

[19] X. Ma, C. Jiang, H. Xu, H. Ding, and S. Shuai, "Laminar burning characteristics of 2-methylfuran and isooctane blend fuels," Fuel, vol. 116, pp. 281-291, 2014.

[20] H. Wei et al., "Experimental investigation on the combustion and emissions characteristics of 2-methylfuran gasoline blend fuel in spark-ignition engine," Appl. Energy, vol. 132, pp. 317-324, 2014.

[21] F. Eslami, M. L. Wyszyński, A. Tsolaskis, H. Xu, S. Norouzi, and K Dearn, "Experimental investigation on lubricity of 2, 5-dimethylfuran blends," Silniki Spalinowe, vol. 51, pp. 3-10, 2012.

[22] E. Hu, X. Hu, X. Wang, Y. Xu, K. D. Dearn, and H. Xu, "On the fundamental lubricity of 2, 5-dimethylfuran as a synthetic engine fuel," Tribol. Int., vol. 55, pp. 119-125, 2012.

[23] A. T. Hoang and M. T. Pham, "Influences of heating temperatures on physical properties, spray characteristics of bio-oils and fuel supply system of a conventional diesel engine," Int. J. Adv. Sci. Eng. Inf. Technol., vol. 8, no. 5, 2018.

[24] M. T. Pham, A. T. Hoang, A. T. Le, A. R. M. S. Al-Tawaha, V. H. Dong, and V. V. Le, "Measurement and prediction of the density and viscosity of biodiesel blends," Int. J. Technol., vol. 9, no. 5, pp. 1015-1026, 2018

[25] W. W. Pulkrabek, Engineering fundamentals of the internal combustion engine. Pearson Prentice Hall Upper Saddle River, 2014.

[26] A. T. Hoang, Q. V. Tran, A. R. M. S. Al-Tawaha, V. V. Pham, and X. P. Nguyen, "Comparative analysis on performance and emission characteristics of an in-Vietnam popular 4-stroke motorcycle engine running on biogasoline and mineral gasoline," Renew. Energy Focus, vol. 28 , pp. 47-55, 2019. 